\title{
Community College Pathways to Medical School and Family Medicine Residency Training
}

Efrain Talamantes, $M D, M B A, M S c^{1,2}$

Anthony Jerant, $M D^{3}$

Mark C. Henderson, $M D^{1,2}$

Erin Griffin, $P b D^{1}$

Tonya Fancher, MD, MPH ${ }^{1,2}$

Douglas Grbic, $\mathrm{PbD}^{4}$

Gerardo Moreno, MD, MSHS

Peter Franks, $M D^{3}$

${ }^{1}$ Center for a Diverse Healthcare Workforce, University of California, Davis School of Medicine, Sacramento, California

${ }^{2}$ Department of Medicine, Division of General Internal Medicine, University of California, Davis School of Medicine, Sacramento, California

${ }^{3}$ Department of Family and Community Medicine, University of California, Davis School of Medicine, Sacramento, California

${ }^{4}$ Association of American Medical Colleges, Washington, DC

${ }^{5}$ Department of Family Medicine, David Geffen School of Medicine at University of California, Los Angeles, Los Angeles, California

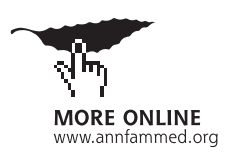

Conflicts of interest: authors report none.

\section{CORRESPONDING AUTHOR}

Efrain Talamantes, MD, MBA, MSc UC Davis School of Medicine Clinical and Translational Science Center (CTSC)

2921 Stockton Blvd, Ste 1408

Sacramento, CA 95817

etalamantes@ucdavis.edu

\begin{abstract}
PURPOSE Medical students who attend community college are more likely to express intention to train in family medicine. This study examined whether community college attendance is associated with family medicine residency training in a national sample of US medical school graduates.
\end{abstract}

METHODS We performed a cross-sectional analysis using the Association of American Medical Colleges matriculant files of residency trainees who graduated from medical school between 2010 to 2012. Residency specialty (family medicine vs other) was modeled using logistic regression analysis; the key independent variable was community college attendance, with categories of non-community college (reference); community college while in high school; community college after graduating from high school, then transfer to 4-year university; and community college after graduating from a 4-year university or as a postbaccalaureate. The logistic model adjusted for age, sex, race/ethnicity, years in medical school, parental education (a marker of socioeconomic status), and high school US region.

RESULTS Of the 43,382 medical school graduates studied, $25.9 \%$ attended community college and $8.7 \%$ trained in family medicine. In unadjusted analysis, graduates attending community college while in high school, after graduating from high school with transfer to 4-year university, or after graduating from a 4 -year university or as a postbaccalaureate $(12.0 \%, 12.7 \%$, and $10.8 \%$, respectively) were more likely to train in family medicine compared with their peers who did not attend community college (7.7\%). Respective adjusted odds ratios were $1.47(95 \% \mathrm{Cl}, 1.33-1.63 ; P<.001), 1.27(95 \% \mathrm{Cl}, 1.06-1.52 ; P=.009)$, and $1.17(95 \% \mathrm{Cl}, 1.06-2.29 ; P=.002)$. Among family medicine residents, $32.7 \%$ of those who were white, $35.2 \%$ of those Asian, $50.8 \%$ of those Latino, and $32.7 \%$ of those black or African American attended community college.

CONCLUSIONS US medical school graduates who attended community college were more likely to train in family medicine, suggesting community college is an important pathway for increasing the primary care workforce.

Ann Fam Med 2018;16:302-307. https://doi.org/10.1370/afm.2270.

\section{INTRODUCTION}

$\mathrm{P}$ opulation growth and health insurance expansion under the Patient Protection and Affordable Care Act demand a vital supply of primary care physicians in the United States. ${ }^{1-4}$ Declining medical student interest in primary care ${ }^{5,6}$ jeopardizes the sustainability and growth of the primary care workforce. Interest in primary care may begin well before medical school and is influenced by demographic characteristics, ${ }^{7,8}$ undergraduate and medical education, ${ }^{9-13}$ and residency training. ${ }^{14}$ US medical students may begin their undergraduate education at a 4-year university or at a community college with plans to transfer to a 4 -year university. According to previous national studies, one-third of medical students attend community college, ${ }^{15}$ and such attendance is positively associated with intentions to practice in family medicine. ${ }^{16}$ Whether these early career intentions are realized, thus contributing to the family medicine physician workforce, has not been explored. 
Premedical community college experiences may influence future specialty interests and choice. ${ }^{16,17} \mathrm{Com}$ munity college students may have stronger community ties, and often work part or full time, nurturing a sense of civic duty prevalent in primary care specialties such as family medicine. ${ }^{17}$ Many high-achieving, low-income high school students enroll in community colleges with plans to transfer to 4 -year universities. ${ }^{18,19}$ Community colleges serve a large proportion of Latino, black or African American, and Asian/Pacific Islander students, who are underrepresented in medicine, as well as firstgeneration college, low-income, and older students. ${ }^{20,21}$ Approximately 7.2 million or $40 \%$ of all undergraduate college students attend community college. Exploring the characteristics of medical students who attend community college may therefore be of interest to those seeking to increase the primary care workforce.

This study examined the associations of community college attendance with family medicine residency training in a national cohort of US doctor of medicine (MD)-granting medical school graduates (USMGs). We hypothesized the community college pathway would be associated with family medicine residency training given prior research supporting intentions of community college students to pursue this specialty. ${ }^{16}$

\section{METHODS}

\section{Data Sources}

We analyzed deidentified data from the Association of American Medical Colleges (AAMC) matriculant files of 50,791 residency trainees who had graduated from medical school between 2010 and 2012. This data set included variables related to undergraduate and medical education and residency training. After excluding missing data, our final study sample consisted of 43,382 medical school graduates ( $85.4 \%$ of the total) 3,910 $(7.7 \%)$ were missing residency specialty, 3,232 (6.4\%) high school region, and $267(0.5 \%)$ race/ethnicity. This study was reviewed and approved by the University of California, Davis Institutional Review Board.

\section{College Pathways}

Our primary predictor was undergraduate college pathway. Undergraduate college pathways to medical school were determined using the Carnegie Classification of Institutions of Higher Education: (1) attended community college during high school (ie, dual enrollment) ${ }_{i}(2)$ attended community college before transferring to a 4-year university ${ }_{i}$ (3) attended community college after graduating from a 4-year university or postbaccalaureate; and (4) never attended community college (non-community college). The rationale for using 3 fundamentally different community college categories was to account for the heterogeneity in community college attendance and is described in prior studies. ${ }^{15,16}$

\section{Measures}

The primary outcome measure was graduate medical residency training specialty (family medicine vs other). Other residency programs included all other specialty options (eg, pediatrics, internal medicine, psychiatry, neurology, dermatology, radiology, surgery, and others). Internal medicine, pediatrics, and internal medicine-pediatrics were presumed to be categorical programs and thus not considered primary care. Residency selection during postgraduate year 2 was used, so as not to include physicians who switched specialties after their first year of training. Other measures included self-reported sex (female or male), age, race/ ethnicity (non-Hispanic white, Asian, black or African American, and Hispanic or Latino), and parental education (less than college or attended college). Time in medical school was calculated as the difference between year of matriculation and year of graduation. Location of each graduate's high school graduation was categorized using US census region-West, Midwest, Northeast, or South-to account for any possible regional variation in community college attendance.

\section{Analysis}

We used Stata version 14.2 (Stata Corp) to conduct analyses. Descriptive statistics included variable frequencies, means, and percentages. Cross-tabulations included unadjusted proportions of students with various characteristics for each outcome. In bivariate analyses, we tested for the statistical significance of unadjusted differences across groups using the $\chi^{2}$ test for categorical variables and the ANOVA test for continuous variables.

Logistic regression analysis was performed to explore the associations between each of the $3 \mathrm{com}$ munity college pathways described above-the key predictor variable - and family medicine residency vs other specialty - the dependent variable. We performed a sensitivity analysis to explore the association between each community college pathway and other potential primary care specialties (internal medicine, pediatrics, and internal medicine-pediatrics vs other specialties). Inclusion of covariates was based on the literature on factors that influence admission to medical school and practice intentions, even if the variables had no statistically significant association in the bivariate analyses. ${ }^{14-17}$ In our unadjusted model, the community college pathways were the independent variables, yielding unadjusted odds ratios (ORs). Our adjusted model added student personal characteristics: age, sex, race/ethnicity, years in medical school, parental education (a marker 
of socioeconomic status), and high school US region, yielding adjusted odds ratios (AORs). We included adjusted marginal percentages to facilitate interpretation of logistic regression findings. A statistical significance level was set at $P<.05$ for all analyses.

\section{RESULTS}

Of the 43,382 USMGs from 2010-2012, 25.9\% attended community college: $11.2 \%$ during high school, $2.9 \%$ before transferring to a 4 -year university, and $11.9 \%$ after graduating from a 4 -year university. Table 1 presents their characteristics overall and by college pathway. The majority of medical graduates obtained a medical doctor degree (MD) rather than an $\mathrm{MD}$-dual degree (eg, MD-PhD). A higher proportion of female, black or African American, and Latino medical graduates attended community college. Those attending community college after graduating from a 4 -year university were older. On average, graduates attended medical school for 4.25 years, with a stan- dard deviation of 0.68 years and range of 4 to 9 years. A higher percentage of community college attendees graduated from a high school in the West region compared with the Northeast region.

Table 2 shows characteristics of graduates who trained in family medicine. Of the 43,382 USMGs studied, $3,787(8.7 \%)$ trained in family medicine. Of this group, 1,298 (34.3\%) attended community college. In unadjusted analysis, a higher percentage of community college attendees trained in family medicine compared with other residency specialties. Among family medicine residents, 860 of 2,631 (32.7\%) of those white, 157 of 446 (35.2\%) of those Asian, 136 of 268 (50.8\%) of those Latino, 107 of 327 (32.7\%) of those black or African American, and 254 of 606 (41.9\%) of those who were first-generation college graduates attended community college. Women, whites, blacks or African Americans, Latinos, first-generation college students, and individuals who completed high school in the West region more commonly became family medicine residents as opposed to residents in other specialties.

Table 1. Characteristics of USMGs 2010-2012 by Undergraduate College Pathway

\begin{tabular}{|c|c|c|c|c|c|c|}
\hline \multirow[b]{2}{*}{ Characteristic } & \multicolumn{5}{|c|}{ Undergraduate College Pathway } & \multirow[b]{2}{*}{ Total } \\
\hline & $\begin{array}{l}\text { Non- } \\
\text { Community } \\
\text { College }\end{array}$ & $\begin{array}{l}\text { High School- } \\
\text { Community } \\
\text { College }\end{array}$ & $\begin{array}{l}\text { Community } \\
\text { College-Transfer }\end{array}$ & $\begin{array}{c}\text { Postbaccalaureate- } \\
\text { Community } \\
\text { College }\end{array}$ & $\begin{array}{c}P \\
\text { Value }^{a}\end{array}$ & \\
\hline All graduates, No. (\%) & $32,138(74.1)$ & $4,846(11.2)$ & $1,241(2.9)$ & 5,157 (11.9) & - & $43,382(100)$ \\
\hline \multicolumn{5}{|l|}{ Program type, No. (\%) } & $<.001$ & \\
\hline MD only & 29,698 (73.6) & $4,535(11.2)$ & $1,187(2.9)$ & $4,930(12.2)$ & & $40,350(100)$ \\
\hline MD dual degree & $2,440(80.5)$ & $311(10.3)$ & $54(1.8)$ & $227(7.5)$ & & $3,032(100)$ \\
\hline Age, mean (SD), y & $23.6(2.2)$ & $23.5(2.2)$ & $25.4(3.4)$ & $24.7(3.2)$ & $<.001$ & $23.7(2.4)$ \\
\hline \multicolumn{5}{|l|}{ Sex, No. (\%) } & $<.001$ & \\
\hline Male & $16,655(74.2)$ & $2,413(10.8)$ & $761(3.4)$ & $2,605(11.6)$ & & $22,434(100)$ \\
\hline Female & $15,483(73.9)$ & $2,433(11.6)$ & $480(2.3)$ & $2,552(12.2)$ & & $20,948(100)$ \\
\hline \multicolumn{5}{|l|}{ Race/ethnicity, No. (\%) } & $<.001$ & \\
\hline White & $21,379(75.1)$ & $3,043(10.7)$ & $745(2.6)$ & $3,318(11.7)$ & & $28,485(100)$ \\
\hline Asian & $6,557(74.1)$ & $1,151(13.0)$ & $226(2.6)$ & $916(10.4)$ & & $8,850(100)$ \\
\hline Black or African American & $1,879(72.7)$ & $238(9.2)$ & $85(3.3)$ & $383(14.8)$ & & $2,585(100)$ \\
\hline Latino & $1,514(64.6)$ & $282(12.0)$ & $159(6.8)$ & $390(16.6)$ & & $2,345(100)$ \\
\hline Multiple & 809 (74.4) & $132(11.8)$ & $26(2.3)$ & $150(13.4)$ & & $1,117(100)$ \\
\hline $\begin{array}{l}\text { Time in medical school, mean } \\
\text { (SD), y }\end{array}$ & $4.25(0.70)$ & $4.25(0.68)$ & $4.27(0.69)$ & $4.21(0.59)$ & $<.001$ & $4.25(0.68)$ \\
\hline $\begin{array}{l}\text { First-generation college student, } \\
\text { No. (\%) }\end{array}$ & $2,893(62.8)$ & $714(15.5)$ & $294(6.4)$ & $706(15.3)$ & $<.001$ & $4,607(100)$ \\
\hline \multicolumn{5}{|l|}{ High school US region, No. (\%) } & $<.001$ & \\
\hline West & $5,174(57.9)$ & 1,924 (21.6) & $479(5.4)$ & $1351(15.1)$ & & $8,928(100)$ \\
\hline Midwest & $8,273(75.0)$ & $1,060(9.6)$ & $267(2.4)$ & $1,426(12.9)$ & & $11,026(100)$ \\
\hline Northeast & $8,255(88.4)$ & $319(3.4)$ & $98(1.1)$ & $671(7.2)$ & & $9,343(100)$ \\
\hline South & $10,436(74.1)$ & $1,543(11.0)$ & $397(2.8)$ & $1,709(12.1)$ & & $14,085(100)$ \\
\hline \multicolumn{7}{|c|}{ USMG = US doctor of medicine (MD)-granting medical school graduate. } \\
\hline \multicolumn{7}{|c|}{$\begin{array}{l}\text { Notes: Non-community college: medical graduates who never attended a community college; high school-community college: medical graduates who attended a } \\
\text { community college while in high school and before graduating from high school; community college-transfer: medical graduates who attended a community college } \\
\text { after graduating from high school and before transferring to a 4-year university; postbaccalaureate-community college: medical graduates who attended a community } \\
\text { college after graduating from a 4-year university. }\end{array}$} \\
\hline \multicolumn{7}{|c|}{ aANOVA test for continuous variables and $\chi^{2}$ test of differences for proportions when both variables were categorical. } \\
\hline
\end{tabular}


Table 2. Comparison of USMGs 2010-2012 Who Trained in Family Medicine Residency vs Other Residency Specialties

\begin{tabular}{|c|c|c|c|}
\hline Characteristic & $\begin{array}{l}\text { Family } \\
\text { Medicine } \\
(n=3,787)\end{array}$ & $\begin{array}{l}\text { Other Residency } \\
\text { Specialties }^{a} \\
(n=39,595)\end{array}$ & P Value ${ }^{b}$ \\
\hline College pathway, No. (\%) & & & $<.001$ \\
\hline Non-community college & $2,489(7.7)$ & $29,649(92.3)$ & \\
\hline High school-community college & $580(12.0)$ & $4,266(88.0)$ & \\
\hline Community college-transfer & $157(12.7)$ & $1,084(87.4)$ & \\
\hline Postbaccalaureate-community college & $562(10.9)$ & $4,596(89.1)$ & \\
\hline Program type, No. (\%) & & & $<.001$ \\
\hline MD only & $3,551(8.8)$ & $36,799(91.2)$ & \\
\hline MD dual degree & $236(7.8)$ & 2,796 (92.2) & \\
\hline Age, mean (SD), y & $23.7(2.4)$ & $24.4(2.9)$ & $<.001$ \\
\hline Female, No. (\%) & $2,245(59.3)$ & $18,703(47.2)$ & $<.001$ \\
\hline Race/ethnicity, No. (\%) & & & $<.001$ \\
\hline White & $2,631(9.2)$ & $25,854(90.8)$ & \\
\hline Asian & $446(5.0)$ & $8,404(95.0)$ & \\
\hline Black or African American & $327(12.6)$ & $2,258(87.4)$ & \\
\hline Latino & $268(11.4)$ & $2,077(88.6)$ & \\
\hline Multiple & $115(10.3)$ & 1,002 (89.7) & \\
\hline Time in medical school, mean (SD), y & $4.31(0.65)$ & $4.24(0.69)$ & $<.001$ \\
\hline First-generation college student, No. (\%) & $606(13.2)$ & $4,001(86.8)$ & $<.001$ \\
\hline High school US region, No. (\%) & & & $<.001$ \\
\hline West & $928(10.4)$ & $8,000(89.6)$ & \\
\hline Midwest & $1,128(10.2)$ & $9,898(89.8)$ & \\
\hline Northeast & $548(5.9)$ & $8,795(94.1)$ & \\
\hline South & $1,183(8.4)$ & $12,902(91.6)$ & \\
\hline \multicolumn{4}{|c|}{ USMG = US doctor of medicine (MD)-granting medical school graduate. } \\
\hline \multicolumn{4}{|c|}{$\begin{array}{l}\text { Notes: Non-community college: medical graduates who never attended a community college; high school-com- } \\
\text { munity college: medical graduates who attended a community college while in high school and before graduat- } \\
\text { ing from high school; community college-transfer: medical graduates who attended a community college after } \\
\text { graduating from high school and before transferring to a 4-year university; postbaccalaureate-community col- } \\
\text { lege: medical graduates who attended a community college after graduating from a 4-year university. }\end{array}$} \\
\hline \multicolumn{4}{|c|}{$\begin{array}{l}\text { aPediatrics, internal medicine, neurology, dermatology, radiology, surgery, and other specialties. } \\
\text { bANOVA test for continuous variables and } \chi^{2} \text { tests of differences for proportions when both variables were } \\
\text { categorical. }\end{array}$} \\
\hline
\end{tabular}

pursuing an internal medicine, pediatrics, or internal medicinepediatrics residency.

\section{DISCUSSION}

To our knowledge, this is the first study to examine the association between undergraduate college pathways and family medicine residency training. After adjusting for confounders, USMGs who attended community college were more likely to train in family medicine when compared with those who never attended community college. Notably, 33\% of whites, $35 \%$ of Asians, $32 \%$ of blacks or African Americans, 51\% of Latinos, and $42 \%$ of first-generation college students within the family medicine residency workforce attended community college. Our findings are also consistent with prior research demonstrating an association between attending community college and interest in family medicine as a specialty. ${ }^{16}$ Furthermore, this study adds to the body of literature on factors associated with family medicine residency. ${ }^{5,7,22}$ Nurturing early interest in family medicine during high school and community college may be a strategy to increase the supply and diversity of the
Table 3 shows the results of the logistic regression analyses. In the adjusted model, medical graduates who attended community college were more likely to train in family medicine compared with those who did not attend community college, a pattern seen across the 3 pathways: attended community college during high school $(\mathrm{AOR}=1.47 ; 95 \% \mathrm{CI}, 1.33-1.63 ; \mathrm{P}<.001)$, attended community college before transferring to a 4 -year university $(\mathrm{AOR}=1.27 ; 95 \% \mathrm{CI}, 1.06-1.52 ; \mathrm{P}=.009)$, and attended community college after graduating from 4 -year university or postbaccalaureate $(\mathrm{AOR}=1.17 ; 95 \% \mathrm{CI}, 1.06-2.29$; $P=.002)$. The area under the receiver operating characteristic curve was 0.65. Supplemental Table 1 (available at http://www.annfammed.org/content/16/4/302/suppl/ DC1/) shows the complete logistic regression analysis, including AORs for all covariates.

Sensitivity analysis revealed that community college attendance was not significantly associated with primary care physician workforce in the United States A greater number of mentoring programs such as the California Future Faces of Family Medicine may help by facilitating collaborations between family medicine physician associations, local family medicine residency programs, medical schools, community colleges, universities, and high schools. ${ }^{23}$

Attending community college before graduating from high school, also referred to as community college dual enrollment, has become much more common in the United States over the past 2 decades. ${ }^{19}$ Twothirds of community college dual enrollment students are from low- or middle-income families. ${ }^{19}$ Future studies should further explore the mechanism by which community college attendance may influence family medicine residency selection. Students attending community college may face additional socioeconomic disadvantages or participate in unique programs that 


\section{Table 3. Odds of Training in Family Medicine Residency Among USMGs 2010-2012 by Undergraduate College Pathway}

\begin{tabular}{|c|c|c|c|}
\hline College Pathway & $\begin{array}{l}\text { Odds Ratio } \\
\text { (95\% CI) }\end{array}$ & $\begin{array}{c}P \\
\text { Value }^{a}\end{array}$ & $\begin{array}{c}\text { Marginal \% } \\
(95 \% \mathrm{CI})\end{array}$ \\
\hline \multicolumn{4}{|l|}{ Unadjusted analysis } \\
\hline Non-community college & Reference & - & $7.7(7.5-8.0)$ \\
\hline High school-community college & $1.62(1.47-1.78)$ & $<.001$ & $12.0(11.1-12.9)$ \\
\hline Community college-transfer & $1.72(1.45-2.05)$ & $<.001$ & $12.7(10.8-14.5)$ \\
\hline Postbaccalaureate-community college & $1.45(1.32-1.60)$ & $<.001$ & $10.9(10.0-11.7)$ \\
\hline \multicolumn{4}{|l|}{ Adjusted analysis ${ }^{b}$} \\
\hline Non-community college & Reference & - & $8.1(7.8-8.4)$ \\
\hline High school-community college & $1.47(1.33-1.63)$ & $<.001$ & $11.4(10.5-12.3)$ \\
\hline Community college-transfer & $1.27(1.06-1.52)$ & .009 & $10.1(8.5-11.6)$ \\
\hline Postbaccalaureate-community college & $1.17(1.06-1.29)$ & .002 & $9.3(8.6-10.1)$ \\
\hline \multicolumn{4}{|c|}{ USMG = US doctor of medicine (MD)-granting medical school graduate. } \\
\hline \multicolumn{4}{|c|}{$\begin{array}{l}\text { Notes: Non-community college: medical graduates who never attended a community college; high } \\
\text { school-community college: medical graduates who attended a community college while in high school } \\
\text { and before graduating from high school; community college-transfer: medical graduates who attended } \\
\text { a community college after graduating from high school and before transferring to a } 4 \text {-year university; } \\
\text { postbaccalaureate-community college: medical graduates who attended a community college after gradu- } \\
\text { ating from a 4-year university. }\end{array}$} \\
\hline \multicolumn{4}{|l|}{ a Wald test. } \\
\hline
\end{tabular}

can Medical College Application medical student data. There may be some residents who do not complete training or decide to switch after the second postgraduate year. It is unclear whether the findings apply to other primary care specialties such as pediatrics or internal medicine because the data did not distinguish between primary care and categorical (non-primary care) specialty residency programs. According to the American College of Physicians, internal medicine residency graduates represent $20 \%$ to $25 \%$ of those entering the primary care workforce, a similar pattern has been reported in pediatric residencies. ${ }^{28}$ It is therefore unlikely that these non-family medicine primary care specialties would substantially affect the findings on the importance of the community college pathway.

In conclusion, attending community college provides a viable pathway for students to pursue a career in medicine and ultimately become primary care physicians. Further strengthening the community college pathway may increase the diversity and supply of the US primary care physician workforce. More research is needed to longitudinally follow high school, community college, and 4-year university students to better understand how various experiences or programs influence their career decisions.

To read or post commentaries in response to this article, see it online at http://www.AnnFamMed.org/content/16/4/302.

Key words: community college; education, premedical; education, medical; minority groups; family medicine; primary care; health workforce

Submitted December 12, 2017; submitted, revised, April 9, 2018; accepted May 8, 2018.

Funding support: This project was supported by the Health Resources and Services Administration (HRSA) of the US Department of Health and Human Services (HHS) under grant number UH1HP29965, Academic Units for Primary Care Training and Enhancement.

Disclaimer: The content and conclusions are those of the authors and should not be construed as the official position or policy of, nor should any endorsements be inferred by, HRSA, HHS, or the US government.

Acknowledgments: The authors would like to thank the Sacramento City College faculty, staff, community partners, and students for inspiring this work.

Supplementary materials: Available at http://www.AnnFamMed. org/content/16/4/302/suppl/DC1/. data file did not include osteopathic or non-Ameri- 


\section{References}

1. Dall T, West T, Chakrabarti R, lacobucci W. The complexities of physician supply and demand: projections from 2013 to 2025. Final report association of American medical colleges. Assoc Am Med Coll. 2015;(March):1-68.

2. Petterson SM, Liaw WR, Phillips RL Jr, Rabin DL, Meyers DS, Bazemore AW. Projecting US primary care physician workforce needs: 2010-2025. Ann Fam Med. 2012;10(6):503-509.

3. US Department of Health and Human Services, Health Resources and Services Administration (HRSA), National Center for Health Workforce Analysis. National and Regional Projections of Supply and Demand for Primary Care Practitioners: 2013-2025. Rockville, MD: HRSA; 2016

4. Kozakowski SM, Travis A, Marcinek JP, Bentley A, Fetter GT Jr. Entry of medical school graduates into family medicine residencies: 20162017. Fam Med. 2017;49(9):686-692.

5. Jeffe DB, Whelan AJ, Andriole DA. Primary care specialty choices of United States medical graduates, 1997-2006. Acad Med. 2010; 85(6):947-958.

6. Association of American Medical Colleges. 2015 State Physician Workforce Data Book. Washington, DC: Association of American Medical Colleges; 2015.

7. Bland CJ, Meurer LN, Maldonado G. Determinants of primary care specialty choice: a non-statistical meta-analysis of the literature. Acad Med. 1995;70(7):620-641.

8. Senf JH, Campos-Outcalt D, Kutob R. Factors related to the choice of family medicine: a reassessment and literature review. J Am Board Fam Pract. 2003;16(6):502-512.

9. Meurer LN. Influence of medical school curriculum on primary care specialty choice: analysis and synthesis of the literature. Acad Med. 1995;70(5):388-397.

10. Lawson SR, Hoban JD. Predicting career decisions in primary care medicine: a theoretical analysis. J Contin Educ Health Prof. 2003; 23(2):68-80.

11. Kost A, Benedict J, Andrilla CHA, Osborn J, Dobie SA. Primary care residency choice and participation in an extracurricular longitudinal medical school program to promote practice with medically underserved populations. Acad Med. 2014;89(1):162-168.

12. Kost A, Cawse-Lucas J, Evans DV, Overstreet F, Andrilla CHA, Dobie S. Medical student participation in family medicine department extracurricular experiences and choosing to become a family physician. Fam Med. 2015;47(10):763-769.

13. Lupton K, Vercammen-Grandjean C, Forkin J, Wilson E, Grumbach K. Specialty choice and practice location of physician alumni of University of California premedical postbaccalaureate programs. Acad Med. 2012;87(1):115-120.

14. Goodfellow A, Ulloa JG, Dowling PT, et al. Predictors of primary care physician practice location in underserved urban or rural areas in the United States: a systematic literature review. Acad Med. 2016; 91(9):1313-1321.
15. Talamantes E, Mangione CM, Gonzalez K, Jimenez A, Gonzalez F, Moreno G. Community college pathways: improving the U.S. physician workforce pipeline. Acad Med. 2014;89(12):1649-1656.

16. Talamantes E, Hernandez AM, Gonzalez R, et al. Interest in family medicine among US medical students and its association with a community college academic pathway. Fam Med. 2017;49(10): 759-764.

17. Talamantes E, Gonzalez K, Mangione CM, et al. Strengthening the community college pathway to medical school: A study of Latino students in California. Fam Med. 2016;48(9):703-710.

18. Hoxby CM, Avery C. The missing "one-offs": the hidden supply of high-achieving, low income students. Brookings Papers on Economic Activity. 2013;(1):1-65.

19. Columbia University CCRC. What We Know About Dual Enrollment. Research Overview. New York, NY: Teachers College, Columbia University; 2012. https://ccrc.tc.columbia.edu/media/k2/attachments/ dual-enrollment-research-overview.pdf. Accessed Aug 12, 2017.

20. Ginder SA, Kelly-Reid JE, Mann FB. Enrollment and Employees in Postsecondary Institutions, Fall 2014; and Financial Statistics and Academic Libraries, Fiscal Year 2014. Washington, DC: US Department of Education; 2014.

21. Ma J, Baum S. Trends in community colleges: enrollment, prices, student debt, and completion. Coll Board Res. 2016:1-23.

22. Phillips JP, Petterson SM, Bazemore AW, Phillips RL. A retrospective analysis of the relationship between medical student debt and primary care practice in the United States. Ann Fam Med. 2014;12(6):542-549.

23. California Academy of Family Physicians Foundation. Future faces of family medicine. CAFP Foundation web site. http://www. cafpfoundation.org/programs/future-faces-of-family-medicine/. Accessed Aug 12, 2017.

24. Fowkes V, Blossom HJ, Mitchell B, Herrera-Mata L. Forging success ful academic-community partnerships with community health centers: the California statewide Area Health Education Center (AHEC) experience. Acad Med. 2014;89(1):33-36.

25. Phillips RL Jr, Bazemore AW. Primary care and why it matters for U.S. health system reform. Health Aff (Millwood). 2010;29(5): 806-810.

26. Bodenheimer T, Pham HH. Primary care: current problems and proposed solutions. Health Aff (Millwood). 2010;29(5):799-805.

27. Spetz J, Coffman J, Geyn I. California's Primary Care Workforce: Forecasted Supply, Demand, and Pipeline of Trainees, 2016-2030. San Francisco, CA: Healthforce Center at UCSF; 2017.

28. Freed GL, Dunham KM, Jones MD Jr, McGuinness GA, Althouse L; Research Advisory Committee of the American Board of Pediatrics. General pediatrics resident perspectives on training decisions and career choice. Pediatrics. 2009;123(Suppl 1):\$26-\$30. 